\title{
Behaviour of a starch as a viscosity modifier for aerial lime-based mortars
}

\begin{abstract}
Different dosages of a commercialized potato starch were added to aerial lime-based mortars in order to check its efficiency as a rheological modifier. Several fresh state properties of the mortars were studied: consistency, density, air content, water retention capacity, setting time and evolution when applied on support. The effect of the starch on $\zeta$-potential of the lime particle surface as well as the particle size distribution and viscosity changes in lime pastes were also assessed in order to elucidate the action mechanism of the polymer. The behaviour of the starch was found to be strongly dosage-dependent: it acted as a thickener when the incorporated dosage was up to $0.30 \%$ of lime weight; conversely, above that dosage, it behaved as a plasticizer. The thickening effect took place because polymer molecules were adsorbed onto lime particles acting as a flocculant, as confirmed by $\zeta$-potential and particle size distribution results. For large amounts of polymer, steric hindrance and electrostatic repulsive forces appeared, leading to a dispersion mechanism which explained the plasticizing effect as well as the fresh mortar behaviour.
\end{abstract}

\section{Introduction}

Starches and starch derivatives have been widely described as rheology-modifying admixtures (Leeman \& Winnefeld, 2007; Ouyang, Jiang, Qiu, Yang \& Pang, 2009; Peschard, Govin, Grosseau, Guilhot, \& Guyonnet, 2004; Rixom \& Mailvaganam, 1999). 
The role they play in mortars is not easily predictable, as there are many factors affecting the influence that a polymer exerts on a mixture, such as: i) the type and properties of the binder; ii) the amount of mixing water; iii) the mixing process; iv) the experimental procedures, and v) the presence and properties of additives (Papo \& Piani, 2004).

The molecular weight of a starch seems to be a critical point affecting its behaviour: high molecular weight polymers tend to agglomerate and produce a thickening effect on the mortars, while low molecular weight polymers can easily be adsorbed on the binder particles' surface, generating steric repulsions (i.e. a dispersing effect) which lead to lower viscosities (Ouyang, Jiang, Qiu, Yang \& Pang, 2009; Vieira, Klemm, Einfeldt \& Albrecht, 2005).

The thickening action of starches and their derivatives (ethers and esters) can be understood by considering the similarity between these molecules and cellulose derivatives, which are the most common products used as viscosity enhancing admixtures (VEA's) or water retaining agents, as reported by Paiva et al. (2009) and Pourchez et al. (2006). Among all the derivatives, hydroxypropyl-methyl-cellulose (HPMC) and hydroxyethyl- methyl-cellulose (HEMC) are the most widely used (Paiva, Esteves, Cachim \& Ferreira, 2009). In general, some of these water-retaining products improve the homogeneity of the mixture, enhance its workability and reduce segregation amongst the components of the mortar. They have also been proved to act as set-retarders (Peschard, Govin, Pourchez, Fredon, Bertrand, Maximilien \& Guilhot, 2006). Furthermore, they improve some of the properties in the hardened state 
(Jolicoeur \& Simard, 1998; Paiva, Silva, Labrincha \& Ferreira, 2006; Paiva, Esteves, Cachim \& Ferreira, 2009).

This kind of additive is able to fix water in the structure, reducing the amount of free water in the mixture and producing an increase in viscosity. Furthermore, their lateral chains can suffer an intertwining process that contributes to further increase the viscosity (Paiva, Silva, Labrincha \& Ferreira, 2006). However, the mechanism of setretarding action of these additives is still not clear, although there are several widespread hypotheses which assume that the water-retaining agent or some of its degradation products could be adsorbed on the cement particles (hydrated and/or anhydrous phases), hindering contact between the binder and the water, thus retarding the hydration reaction (Jolicoeur \& Simard, 1998; Pourchez, Govin, Grosseau, Guyonnet, Guilhot \& Ruot, 2006; Pourchez, Peschard, Grosseau, Guyonnet, Guilhot \& Vallee, 2006). Some authors accept that this adsorption takes place through a process in which organic molecules (such as this kind of admixture) fix metallic ions by complexing or chelating, calcium being the most important such ion (Pourchez, Govin, Grosseau, Guyonnet, Guilhot \& Ruot, 2006).

However, as Paiva et al. reported (Paiva, Silva, Labrincha \& Ferreira, 2006), HPMC could also act as a water-reducing agent, showing that polymers present a complex dosage-dependent behaviour. They determined the plastic viscosity and the yield stress of cement mortars with different amounts of HPMC, observing that, when the dosage of additive was lower than $0.08 \%$-of the total dried mortar weight - it produced a plastifying effect. From that dosage to $0.25 \%$, the polymer acted as a thickener. They found an explanation based on two factors: i) samples with low amounts of HPMC 
presented high entrapped air content, which could lead to higher plasticity; ii) the mixing process could disaggregate the entanglement of the chains, producing an alignment with the flow direction which reduced viscosity (Paiva, Silva, Labrincha \& Ferreira, 2006).

In connection with the use of starch and starch derivatives, Leemann and Winnefeld (2007) added a starch derivative to cement mortars and concretes with a superplastizicer, noticing that rheological properties of mortars were scarcely modified, while some properties of concrete were affected: the slump in flow table test and the compactability of the material decreased. Therefore, the starch derivative acted as a thickener in this case.

Glenn et al. (1998) prepared lightweight concretes with starch aquagels as admixtures. These additives were selected because they were able to absorb a large amount of water that, once in the concrete matrix, could easily be caught by the cement. As a result, the polymer suffered a shrinkage process which generated voids and made it possible to reduce the density of the hardened material. The behaviour of the polymer was typical of water retainers.

The dispersing effect of starch derivatives has been reported in many studies. In these cases, these additives have been presented as water-reducing agents or superplasticizers, as quoted by Glenn et al. (1998), Ouyang et al. (2009); Peschard et al (2004), Vieira et al. (2005) and Zhang et al. (2007, 2008). 
Water-reducing agents or plasticizers are additives which make it possible to reduce the water content of a mixture without modifying its consistency, or to improve the workability without varying the amount of mixing water (Papo \& Piani, 2004). Most of the conventional water reducers are condensation products of formaldehyde (such as naphthalene sulfonated formaldehyde condensates and sulfonated melamine formaldehyde condensates) or polymer compounds like polycarboxylate, as reported by Peng et al. (2005), Vieira et al. (2005) and Zhang et al. (2007, 2008). The first ones (formaldehyde derivatives) are high-molecular-weight products that, when dissolved in water, generate high-molecular-weight anions that can be adsorbed on the particle surface, leading to mutual repulsion of individual particles and to a reduction in the inter-particle friction. This dispersion avoids the flocculation of the particles, thus reducing the amount of water required to get a set consistency (Peng, Qu, Zhang, Chen \& Wan, 2005; Seabra, Paiva, Labrincha \& Ferreira, 2009; Zhang, Ju, Zhang, He \& Yang, 2007). The second group of water-reducers (polycarboxylates) avoids flocculation by means of a combination of electrostatic repulsive force and steric hindrance, due to their comb-shape (Peng, Qu, Zhang, Chen \& Wan, 2005; Zhang, Ju, Zhang, He \& Yang, 2007). Formaldehyde derivatives and polycarboxylate-type plasticizers are not biodegradable, and may release formaldehyde into environment, leading to undesirable effects. Some previous works have suggested the use of starch ethers as water-reducing agents, in order to avoid any environmental problem (Vieira, Klemm, Einfeldt \& Albrecht, 2005; Zhang, Ju, Zhang, He \& Yang, 2007; Zhang, Ju, Zhang \& Yang, 2008).

Zhang et al. (2007) studied the effect of starch sufonate in cement pastes, concluding that it showed a more powerful water-reducing action than traditional naphthalene 
sulfonated formaldehyde condensates because, in the case of the starch ether, a strong steric hindrance was the main dispersing mechanism. Vieira et al. (2005) obtained sulfoethyl starches with lower molecular weight than commercial ones, and reported that the effect of these products on some rheological properties of cement pastes (such as slump) was the same or even better than that of polycarboxylate ethers. According to these authors, commercialized starch and cellulose ethers show such a high molecular weight that their efficiency as dispersants becomes reduced, leading to a thickening effect. Peschard et al. (2004) studied the performance of five different powder polysaccharides in cement pastes, and found that the starch ether was the most effective in prolonging the setting time.

Some investigations have been carried out on lime-based materials with water-retaining agents and plasticizers, but so far no research has focused on the incorporation of starch in the mixtures. Seabra et al. (2009) studied the influence of some admixtures on the rheological behaviour of lime mortars. They concluded that HPMC initially exerted a thickening effect on the mixtures but, after some shaking time, this tendency was reversed, due to excessive entry of air. They also incorporated a sulfonated melamine formaldehyde superplasticizer in the mixtures, reporting an increase in the initial and final slump, a considerable increase in the yield stress and a decrease in the torque value of the mortars. Fortes-Revilla et al. (2006) incorporated a polycarboxylate polyoxyethylene to a slaked lime-metakaolin mortar, and obtained significant improvements: i) setting time was reduced; ii) the amount of calcite was higher than the one of the control mortar without additive; iii) the porosity level was lower, and iv) maximum mechanical strengths were larger and reached in a shorter time. 
The rationale of the present study is that the water-reducing action of starches could be specially desirable in lime based mortars, as these materials harden through two mechanisms: i) loss of excess water and subsequent compaction of the material and ii) the carbonation process, which starts during the first steps of setting and can last several years. If the amount of mixing water is larger, the loss of its excess becomes slower, and also the excess of water prevents $\mathrm{CO}_{2}$ from gaining access to the mortar, thus slowing down the carbonation process. On the other hand, the thickening effect of starch is supposed to enhance the workability and to give non-sag and anti-slip properties to the mixtures, improving the pump ability in spray-on mortars and producing a thickening effect which makes it possible to reduce the number of repair cycles, which means a major advantage in repair work that must be completed in a short period of time (Rixom \& Mailvaganam, 1999). The indicated properties would also be desirable to improve the performance of lime-based renders.

The aim of the present paper is to study the influence of a commercialized potato starch on different properties of lime-based mortars. The behaviour of different polymer dosages is assessed and related to a different mechanism of action. Several fresh state properties of the mortars are studied, in order to check the efficiency of the product as a rheology-modifier: consistency, density, air content, water retention capacity, setting time and evolution when applied on supports are reported. Experimental research on the effect of the starch on $\zeta$-potential of lime particles surface as well as the particle size distribution and viscosity changes in lime pastes are also conducted in order to elucidate the action mechanism. The dosage of the polymer was found to be critical for showing either thickening effect or dispersing action. 


\section{Materials}

An aerial commercial lime and a pure limestone aggregate were used to prepare the mortars. The lime (class CL 90-S according to Spanish and European standard (UNE 459-1, 2001) was supplied by Calinsa (Navarra). The aggregate was supplied by Caleras de Liskar (grupo HORPASA), and was a calcareous type. Materials characterization as well as their grain size distribution were previously reported (Izaguirre, Lanas \& Alvarez, in press). The selected binder: aggregate ratio (B:Ag) was $1: 1$, by volume. This decision was taken according to previous data (Lanas \& Alvarez, 2003; Lanas, Perez Bernal, Bello \& Alvarez, 2006). Volume proportions were converted into weight in order to avoid any imprecise measurements. Seven different dried mixtures were prepared by mixing $341,7 \mathrm{~g}$ of lime and $1286.9 \mathrm{~g}$ of aggregate. One of them was composed only of these two main components, and was taken as a control mortar. A commercialized potato starch (PS) was incorporated into the other six mixtures, using a different dosage in each case. The dosages tested were $0.03,0.06,0.15,0.30,0.50$ and $0.80 \%$ of the total dried mortar's weight, and samples were named from PS- 1 to PS- 6 . All of these dosages are in line with previously used dosages of traditional water reducers and starches, as reported by Fortes-Revilla et al. (2006), Glenn et al. (1998), Seabra et al. (2009), Vieira et al. (2005) and Zhang et al. (2008) and include a wide range in order to study the influence of the dosage of additive in the properties of mortars. The The polymer was obtained from a supplier (OPAGEL CMT ${ }^{\circledR}$, AVEBE) $^{\circ}$ that describes it as a natural modified potato starch, with around $80 \%$ of amylopectin and $20 \%$ of amylose. Furthermore, pure soluble starch (Merck, product number: 101252) was analysed in order to compare it with the admixture. Figure 1 shows the IR spectra of both products, showing the huge similarity between them. Little modification, 
if any, was performed on natural potato starch with respect to functional groups to obtain the additive.

In order to obtain more information about the polymer characteristics, the molecular weight distribution of a very diluted solution with $0.02 \%$ of potato starch in water was obtained by means of dynamic light scattering (DLS). A simple cumulant analysis, which gives size information at a particular angle, was used (Chiou, Fellows, Gilbert \& Fitzgerald, 2005). The obtained hydrodynamic radius was $214 \mathrm{~nm}$. This result matched the one previously reported by Roger et al. (1999) for low amylose starch, and confirmed the information given by the supplier about the low amount of amylose in the polymer.

\section{Methods}

\subsection{Mortar preparation}

The amount of water was set according to the criterion of achieving a workable reference material, which is supposed to be related to the slump value obtained during the flow table test. The required amount of water to have a slump of $160 \pm 10 \mathrm{~mm}$ for the reference mortar was $410 \mathrm{~mL}$. This value allowed good workability while avoiding an excess of water which would be damaging for mechanical strengths (Lanas \& Alvarez, 2003). As the tested additive modified the rheology of the mixtures, the workability of mortars with PS was different from that of the reference material when the same amount of mixing water was incorporated, thus modifying the flow table test results. 
Lime, aggregate and PS, if necessary, were blended for 5 minutes using a solid mixer BL-8-CA (Lleal S.A.). Water was then added and mixed for 90 seconds at low speed, in a Proeti ETI 26.0072 mixer. Mortars settled for 10 minutes before being tested, to let the additive take effect. Straight afterwards, fresh state properties were determined as described below.

\subsection{Fresh mixtures}

\subsubsection{Fresh state mortar behaviour}

For the fresh state of mortars, the following properties were studied according to the quoted standardized methods: consistency, through the flow table test, by measuring the slump (UNE 1015-3, 2000); density and air content, both data being recorded using a receptacle of $1 \mathrm{dm}^{3}$ previously weighed, which, after being filled with fresh mortar, was weighed again to obtain the density (UNE 1015-6, 1999). In a specific device, the entrained air was removed and replaced by a measurable amount of introduced water, which allowed us to determine the air content (UNE 1015-7, 1999); water-retention capacity, determined by weighing absorbent materials placed on the fresh sample before and after 5 minutes of contact under pressure (UNE 83-816-93, 1993); and setting time, obtained from a specific device provided with a bradawl, which pushed the fresh sample until the strength exerted to introduce it into the sample was larger than $15 \mathrm{~N}$ (UNE 1015-9, 2000). The evolution of the mortars when applied on support was assessed. This last test consisted of spreading a $15 \mathrm{~mm}$ layer of mortar on a brick and observing any developments. 


\subsection{2. $\zeta$-potential}

Specific mixtures of lime, water, and additive were prepared to assess the viscosity, $\zeta$ potential and the particle size distribution, with a view to elucidating the mechanism through which the polymer acts.

The determination of $\zeta$-potential of solid-liquid interface permitted us to study the dispersing action of an additive, as the adsorption of the admixture on the solid surface of binder modifies this property, as stated by Papo \& Piani, 2004 and Zhang et al. (2007, 2008). Zhang et al. $(2007,2008)$ studied the dispersing mechanism of starch sulfonato, carboxymethyl starch and a starch succinate half ester as water-reducing agents for cement, and observed that an increase in the polymer content led to a decrease in the $\zeta$ potential of the mixtures. They concluded that the adsorption of the admixture changed the charge distribution of the double-electrical layer on the cement surface, due to electrical and steric repulsive forces.

Following the method proposed by Zhang et al. (2007, 2008), solutions with different concentrations of PS were prepared (from 0 to $1.4 \% \mathrm{w} / \mathrm{w}$ ), and lime was added with a solute/liquid ratio of 0.0025 . After 5 minutes of stirring, the mixtures were separated by centrifuge, and the supernatants were analysed using a Zeta Potential Analyzer ZETA PLUS (Brookhaven Instruments Corporation, New York, U.S.A). The average of ten measurements was regarded as the $\zeta$-potential of the lime particles. 


\subsubsection{Particle size distribution}

As was mentioned in the Introduction to this paper, thickeners are able to fix water on their structure and suffer an intertwining process, the consequence being an increase in viscosity (Paiva, Silva, Labrincha \& Ferreira, 2006). Fixation of water and entanglement of chains should produce agglomerates, and particle size distribution of mixtures should change as a result, as mentioned by Chiou et al. (2005), Khayat (1998), Roger et al. (1999) and Saric-Coric et al. (2003).

$3 \mathrm{~g}$ of lime was added to $15 \mathrm{~g}$ of solutions with different amounts of PS in water (from 0 to $1.4 \% \mathrm{w} / \mathrm{w}$ ), the resulting PS/lime ratios ranging from 0 to $7 \% \mathrm{w} / \mathrm{w}$. The particle size distribution of these samples was determined using a Malvern Mastersizer (Malvern Instruments, Ltd., U.K.).

\subsubsection{Apparent viscosity}

The role of a thickener in a mixture consists of increasing the apparent viscosity, while a plasticizer is supposed to produce a decrease in this property, as quoted by Paiva et al. (2006), Papo \& Piani (2004), Sobisch \& Lerche (2008) and Vieira et al. (2005). Lime pastes were prepared by mixing $10 \mathrm{~g}$ of lime, $10 \mathrm{~g}$ of water and different amounts of the potato starch $(0,0.03,0.06,0.15,0.30,0.50$ and $0.80 \%$ of lime weight $)$, and their viscosities were determined using a HAAKE Viscotester VT 550, with a programme of

rotation speeds increasing from 0 to $50 \mathrm{~s}^{-1}$ during 90 seconds and then decreasing from 50 to $0 \mathrm{~s}^{-1}$ in the same time. 


\section{Results and discussion}

\subsection{Fresh state mortar behaviour}

In the present study, the reference mortar was prepared with the required amount of water in order to reach the set value during the flow table test. When PS was incorporated in dosages from 0.03 to $0.30 \%$, lower results of slump were obtained, the effect being more important for higher amounts of admixture. However, when the dosage of $0.50 \%$ was used, a change in the behaviour of the material occurred: the fluidity became higher than the three previous ones and the workability was better, thus marking a critical point. The highest dosage followed the same trend, showing the highest slump values (Fig. 2). Analysing these results, it can be said that PS behaved as a thickener for dosages until $0.30 \%$, and started to plasticize the mortars above that value.

As Figure 3 shows, the incorporation of PS always led to an increase in the air content of the mortars. The percentages of entrained air are comparable to those obtained by Vieira et al. (2005) in cement mortars with starch derivatives. In fact, water-soluble synthetic and natural organic polymers classified as viscosity-enhancing admixtures (VEA's) have inherent surfactant properties that lower the surface tension of the aqueous phase of the paste, giving rise to air entrainment (Khayat, 1998; Seabra, Paiva, Labrincha \& Ferreira, 2009). This air entrainment could explain, broadly speaking, the decrease in the density of the mortars (Fig. 4). 
Regarding the water retention ability, PS-5 and PS-6 showed a considerably greater water retention capacity, the highest dosage leading to a value of $99.6 \%$ (Fig. 5). This water-retaining behaviour can be explained on the grounds that the structure of starches is very similar to that of cellulose derivatives (the most widespread water-retaining agents) (Paiva, Esteves, Cachim \& Ferreira, 2009). Functional hydrophilic groups in the starch molecules would be able to bind water molecules by means of hydrogen bonds. Nevertheless, only the highest amounts of PS led to higher water retentions than the control mortar, which suggests that the polymer behaves in a dosage-dependent manner.

The aforementioned water retention ability can be easily related to the setting time changes (Fig. 6). The large water retention capacity showed by PS-5 and PS-6 mortars could explain the delay in setting time, due to the fact that lime-based mortars must lose the excess water as a first step in the setting process. In spite of having the same amount of water, PS modified the setting time of the mortars, which showed its efficiency as a rheological modifier.

Figure 7 shows the appearance of the layers of mortar 30 minutes after their application on bricks. The selected bricks had a very high water-absorption coefficient, in order to accelerate the evolution of mortars.

The control mortar showed a large number of macroscopic fissures, produced because of the high water absorption coefficient of brick. When the potato starch was incorporated, the mortar presented no cracks, but the adherence was clearly affected by the dosage. As the amount of additive increased to $0.30 \%$, the coherence of the mortar and its adherence to the brick's surface decreased, with a fall in PS-4. This behaviour 
fitted perfectly with the thickening effect observed in the flow table test and with the moderate water retention capacity of the mixtures. PS-5, which proved a workable and coherent material with high water retention capacity, permitted good adherence. The highest dosage led to a mortar that was too liquid, which made it impossible to get the brick up, because it slipped.

\subsection{Discussion on the action mechanism of the polymer}

$\zeta$-potential data of solid-liquid interface of samples with different amounts of PS (Fig. 8) were collected in order to elucidate any interaction between the polymer and the lime particle surface. Hydroxyl groups of the starch molecules should be ionized at the strong alkaline $\mathrm{pH}$ of the lime solution. The adsorption of the polymer onto the lime particles would change their $\zeta$-potential, shifting it towards more negative results. It can be observed that the sample without PS showed the more positive value of $\zeta$-potential $(39.93 \mathrm{mV})$ and the addition of the starch led to a reduction in this value, thus indicating an adsorption of the admixture on the lime surface. These results are in line with those reported by Zhang et al. $(2007,2008)$ from $\zeta$-potential of cement particles with starch ethers added.

Figure 9 shows the particle size distribution of lime pastes containing different amounts of PS (from 0 to $7 \%$ of lime weight). It can be seen that lime paste without additive ( $0 \%$-PS sample) presented two main peaks: a small one corresponding to particles between 0.1 and $1 \mu \mathrm{m}$ and a larger one between 10 and $100 \mu \mathrm{m}$. The paste with $1 \%$ of potato starch (its ratio PS/lime was equivalent to an intermediate dosage between PS-3 and PS-4 mortars) produced a considerable displacement of the main peak toward 
higher values (between 100 and $1000 \mu \mathrm{m}$ ) and a huge increase in its intensity, thus showing the flocculant action between particles produced by this additive. The formation of large-size particles could thus explain the thickening effect of the starch up to $0.30 \%$ : it produced a fluidity drop in the flow table test (Fig. 2) and lower adherences when applied on bricks (Fig. 7).

However, when PS was added in dosages above $2 \%$ of lime weight (equivalent to PS-5 mortar) the intensity of the peak between 100 and $1000 \mu \mathrm{m}$ underwent a dramatic decrease, and the distribution became wider and centred on smaller sizes (from 10 to $300 \mu \mathrm{m})$.

On the basis of the experimental results obtained in the present study, it is evident that potato starch acted as a thickener in lime-based mortars when it constituted up to $0.30 \%$ of the total dried mortar weight. This thickening behaviour with starch addition is clearly different to that reported by Zhang et al. $(2007,2008)$ for different starch ethers in cement pastes. In those studies, starch ethers -in all the tested dosages- acted as dispersing agents, with deflocculant behaviour which gave rise to a plasticizing effect. Nevertheless, in the present research, for samples up to $0.30 \%$ of admixture, starch acted as a flocculant agent, giving rise to interactions between lime particles and polymer molecules, thus explaining the $\zeta$-potential results, particle size distribution in lime pastes as well as the fresh state behaviour of modified mortars. Adsorption of the starch molecules on the lime particle surface may be caused by the hydrophilic functional groups, which act as "lime-anchoring" groups, just as functional groups in other polysaccharides have been reported to act in cement materials (Knaus \& Bauer- 
Heim, 2003; Zhang, Ju, Zhang, He \& Yang, 2007; Zhang, Ju, Zhang \& Yang, 2007; Zhang, Ju, Zhang \& Yang, 2008).

When the dosage was larger than $0.30 \%$, the behaviour changed and the product behaved as a plasticizer (Fig. 2). Particle size distribution showed a dramatic decrease in large particles for these samples, which suggests that the interaction between chains of polymer themselves and between lime particles and starch molecules were, at least, partially broken. Steric hindrance as well as electrostatic repulsions between chains might be generated due to the large amount of added polymer, resulting in dispersion of particles and, as a consequence, a plasticizing effect. This dispersing mechanism could be similar to that proposed by Zhang et al. $(2007,2008)$ to explain the effect of starch ethers in cement materials.

Mortars PS-5 and PS-6 thus corresponded to dosages of polymer in which it was executing a dispersing effect on the lime particles. The dispersion of lime, as well as the break of the linkages between additive chains and lime particles, could generate polymer molecules with many free sites and more dispersed lime particles where water could be fixed, thus explaining the high water retention capacity of those mortars.

In the end, viscositiy measurements (Fig. 10) of lime pastes with different amounts of the tested starch showed a shear-thining behaviour for the measured samples. This behaviour can be very useful for many practical functions (such as rendering, grouts, and shotcrete), because materials of pseudoplastic nature are supposed to resist sedimentation and sagging at rest but can be easily mixed, pumped and sprayed (Rixom \& Mailvaganam, 1999; Yahia \& Khayat, 2001). These materials are able to increase 
viscosity at low shear rates but show a reduction when great stress is applied (for example, when materials are pumped or sprayed during a "wet-mix" or "dry-mix" process) (Rixom \& Mailvaganam, 1999). When the stress is applied, linkages between polymer and lime particles may break, and linear chains of the polymer could align with the flow direction, thus causing a fall in viscosity. When the stress slows down, a recoagulation process could take place (Wallevik, 2009). In the samples studied, the recovery of viscosity when shear rate decreased was not complete, but was satisfactory in all the modified pastes (Fig. $10 \mathrm{~b}$ ).

On the other hand, although mortar fluidity (Fig. 2) and viscosity of lime pastes modified with starch addition are not directly related, there was a general trend: higher amounts of the tested starch led to higher apparent viscosity values up to $0.30 \%$ of PS. Differences between the mortar behaviour in terms of fluidity and paste viscosity could be related to both the effect of the aggregate (Günduz, Bekar \& Sapci, 2007; Nedhi \& Rahman, 2004; Seabra, Paiva, Labrincha \& Ferreira, 2009) and the slip phenomenon, which has been reported to take place when a coaxial cylinders model is used to obtain viscosity data (Nedhi \& Rahman, 2004; Saak, Hamlin \& Shah, 2001).

\section{Conclusions}

A commercialized potato starch was tested as an additive for aerial lime-based mortars. Different dosages of the polymer were added to mortars and several properties at fresh state were studied in order to check their possible efficiency as a rheological modifier. Lime pastes with different amounts of polymer were also prepared to elucidate the action mechanism of the admixture. 
The behaviour of the polymer was found to be strongly dosage-dependent. When up to $0.30 \%$ of lime weight was added, the potato starch acted as a flocculant agent, giving rise to interactions between lime particles and polymer molecules, proved by $\zeta$-potential measurements of the lime particles surface and particle size distributions of lime-starch suspensions. Adsorption of the starch molecules on the lime particle surface could be caused by the hydrophilic functional groups, which act as "lime-anchoring" groups. This thickening effect led to an increase in viscosity values and a decrease in workability and adherence of the material.

On the other hand, dosages of potato starch above $0.30 \%$ of lime weight produced a change in the behaviour of the polymer, which started to act as a plasticizer. Steric hindrance and electrostatic repulsions between chains might be generated due to the large amount of added polymer, resulting in dispersion of particles and, as a consequence, a plasticizing effect, proved by particle size distribution results. Consequently, mortars became flowable and their adherence increased. Furthermore, their water retention capacity became greater, which could be related to the dispersion of lime and the break of linkages between additive chains and lime particles, which could generate many free sites where water could be fixed.

Both dosage-dependent effects produced by the tested polymer can be very useful for many practical application (such as rendering, grouts, and shotcrete), in which pseudoplasticity, adherence and sometimes thickening or plasticizing abilities of the mortars (depending on the application) are critical. 


\section{References}

Chiou et al., 2005

H. Chiou, C.M. Fellows, R.G. Gilbert, M.A. Fitzgerald

Study of rice-starch structure by dynamic light scattering in aqueous solution

Carbohydrate Polymers, 61 (2005), pp. 61-71

Fortes-Revilla et al., 2006

C. Fortes-Revilla, S. Martinez-Remirez, M.T. Blanco-Varela

Modelling of slaked-lime metacaolin mortar engineering characteristics in terms of process variables

Cement and Concrete Composites, 28 (2006), pp. 458-467

Glenn et al., 1998

G.M. Glenn, R.M. Miller, W.J. Orts

Moderate strength lightweight concrete from organic aquagel mixtures

Industrial Crops and Products, 8 (1998), pp. 123-132

Günduz et al., 2007

L. Günduz, M. Bekar, N. Sapci

Influence of a new type of additive on the performance of polymer-lightweight mortar composites

Cement and Concrete Composites, 29 (2007), pp. 594-602

Izaguirre et al., 2009

Izaguirre, J. Lanas, J.I. Alvarez

Effect of water-repellent admixtures on the behaviour of aerial lime-based mortars

Cement \& Concrete Research, 39 (2009), pp. 1095-1104

Jolicoeur and Simard, 1998

Jolicoeur, M.A. Simard

Chemical admixture-cement interactions: Phenomenology and physico-chemical concepts

Cement and Concrete Composites, 20 (1998), pp. 87-101

Khayat, 1998

K.H. Khayat

Viscosity-enhancing admixtures for cement-based materials - An overview

Cement and Concrete Composites, 20 (1998), pp. 171-188

Knaus and Bauer-Heim, 2003

S. Knaus, B. Bauer-Heim

Synthesis and properties of anionic cellulose ethers: Influence of functional groups and molecular weight on flowability of concrete

Carbohydrate Polymers, 53 (2003), pp. 383-394

Lanas and Alvarez, 2003

J. Lanas, J.I. Alvarez

Masonry repair lime-based mortars: Factors affecting the mechanical behaviour

Cement \& Concrete Research, 33 (2003), pp. 1867-1876 
Lanas et al., 2006

J. Lanas, J.L. Perez Bernal, M.A. Bello, J.I. Alvarez

Mechanical properties of masonry repair dolomitic lime-based mortars

Cement \& Concrete Research, 36 (2006), pp. 951-960

Leeman and Winnefeld, 2007

Leeman, F. Winnefeld

The effect of viscosity modifying agents on mortar and concrete

Cement \& Concrete Research, 29 (2007), pp. 341-349

Nehdi and Rahman, 2004

M. Nehdi, M.A. Rahman

Estimating rheological properties of cement pastes using various rheological models for different test geometry, gap and surface friction

Cement \& Concrete Research, 34 (2004), pp. 1993-2007

Ouyang et al., 2009

X. Ouyang, X. Jiang, X. Qiu, D. Yang, Y. Pang

Effect of molecular weight of sulfanilic acid-phenol-formaldehyde condensate on the properties of cementitious system

Cement \& Concrete Research, 39 (2009), pp. 283-288

Paiva et al., 2009

H. Paiva, L.P. Esteves, P.B. Cachim, V.M. Ferreira

Rheology and hardened properties of single-coat render mortars with different types of water retaining agents

Construction and Building Materials, 23 (2009), pp. 1141-1146

Paiva et al., 2006

H. Paiva, L.M. Silva, J.A. Labrincha, V.M. Ferreira

Effects of a water-retaining agent on the rheological behaviour of a single-coat render mortar

Cement \& Concrete Research, 36 (2006), pp. 1257-1262

Papo and Piani, 2004

Papo, L. Piani

Effect of various superplasticizers on the rheological properties of Pórtland cement pastes

Cement \& Concrete Research, 34 (2004), pp. 2097-2101

Peng et al., 2005

J. Peng, J. Qu, J. Zhang, M. Chen, T. Wan

Adsorption characteristics of water-reducing agents on gypsum surface and its effect on the rheology of gypsum plaster

Cement \& Concrete Research, 35 (2005), pp. 527-531

Peschard et al., 2004

Peschard, A. Govin, P. Grosseau, B. Guilhot, R. Guyonnet

Effect of polysaccharides on the hydration of cement pastes at early ages 
Cement \& Concrete Research, 34 (2004), pp. 2153-2158

Peschard et al., 2006

Peschard, A. Govin, J. Pourchez, E. Fredon, L. Bertrand, S. Maximilien et al.

Effect of polysaccharides on the hydration of cement suspension

Journal of the European Ceramic Society, 26 (2006), pp. 1439-1445

Pourchez, Govin et al., 2006

J. Pourchez, A. Govin, P. Grosseau, R. Guyonnet, B. Guilhot, B. Ruot

Alkaline stability of cellulose ethers and impact of their degradation products on cement hydration

Cement \& Concrete Research, 36 (2006), pp. 1252-1256

Pourchez, Peschard et al., 2006

J. Pourchez, A. Peschard, P. Grosseau, R. Guyonnet, B. Guilhot, F. Vallee

HPMC and HEMC influence on cement hydration

Cement \& Concrete Research, 36 (2006), pp. 288-294

Rixom and Mailvaganam, 1999

R. Rixom, N. Mailvaganam

Chemical admixtures for concrete

E \& FN SPON, London (1999)

Roger et al., 1999

P. Roger, L.A. Bello-Perez, P. Colonna

Contribution of amylose and amylopectin to the light scattering behaviour of

starches in aqueous solution

Polymer, 40 (1999), pp. 6897-6909

Saak et al., 2001

A.W. Saak, M.J. Hamlin, S.P. Shah

The influence of wall slip on yield stress and viscoelastic measurements of cement paste

Cement \& Concrete Research, 31 (2001), pp. 205-212

Saric-Coric et al., 2003

M. Saric-Coric, K.H. Khayat, A. Tagnit-Hamou

Performance characteristics of cement grouts made with various combinations of high-range water reducer and cellulose-based viscosity modifier

Cement \& Concrete Research, 33 (2003), pp. 1999-2008

Seabra et al., 2007

M.P. Seabra, J.A. Labrincha, V.M. Ferreira

Rheological behaviour of hydraulic lime-based mortars

Journal of the European Ceramic Society, 27 (2007), pp. 1735-1741

Seabra et al., 2009

M.P. Seabra, H. Paiva, J.A. Labrincha, V.M. Ferreira

Admixtures effect on fresh state properties of aerial lime based mortars

Construction and Building Materials, 23 (2009), pp. 1147-1153 
Sobisch and Lerche, 2008

T. Sobisch, D. Lerche

Thickener performance traced by multisample analytical centrifugation

Colloids and Surfaces, 331 (2008), pp. 114-118

UNE 1015-3, 2000

UNE 1015-3. (2000). Methods of test for mortar for masonry. Part 3: Determination of consistence of fresh mortar (by flow table).

UNE 1015-6, 1999

UNE 1015-6. (1999). Methods of test for mortar for masonry. Part 6: Determination of bulk density of fresh mortar.

UNE 1015-7, 1999

UNE 1015-7. (1999). Methods of test for mortar for masonry. Part 7: Determination of air content of fresh mortar.

UNE 1015-9, 2000

UNE 1015-9. (2000). Methods of test for mortar for masonry. Part 9: Determination of workable life and correction time of fresh mortar.

UNE 459-1, 2001

UNE 459-1. (2001). Building lime. Part 1. Definition, specification and conformity criteria.

UNE 83-816-93, 1993

UNE 83-816-93. (1993). Test methods. Mortars. Fresh mortars. Determination of water retentivity.

Vieira et al., 2005

M.C. Vieira, D. Klemm, L. Einfeldt, G. Albrecht

Dispersing agents for cement based on modified polysaccharides

Cement \& Concrete Research, 35 (2005), pp. 883-890

Wallevik, 2009

J.E. Wallevik

Rheological properties of cement paste: Thixotropic behavior and structural breakdown

Cement \& Concrete Research, 39 (2009), pp. 14-29

Yahia and Khayat, 2001

Yahia, K.H. Khayat

Analytical models for estimating yield stress of high-performance pseudoplastic

grout

Cement \& Concrete Research, 31 (2001), pp. 731-738

Zhang, Ju, Zhang, He et al., 2007

D.F. Zhang, B.Z. Ju, S.F. Zhang, L. He, J.Z. Yang 
The study on the dispersing mechanism of starch sulfonate as a water-reducing agent for cement

Carbohydrate Polymers, 70 (2007), pp. 363-368

Zhang et al., 2007

D.F. Zhang, B.Z. Ju, S.F. Zhang, J.Z. Yang

Dispersing mechanism of carboxymethyl starch as water-reducing agent

Journal of Applied Polymer Science, 105 (2007), pp. 486-491

Zhang et al., 2008

D.F. Zhang, B.Z. Ju, S.F. Zhang, J.Z. Yang

The study on the synthesis and action mechanism of starch succinate half ester as water-reducing agent with super retarding performance

Carbohydrate Polymers, 71 (2008), pp. 80-84

\section{Acknowledgements}

The authors want to thank CTH Navarra and Fernando Moreno (Calinsa S.A. Navarra) for the material supplied. We are also grateful to the staff in Laboratorio de Edificación

(Universidad de Navarra) for their material support and invaluable help, and to Jordi Sintes (AVEBE) for the information provided. 


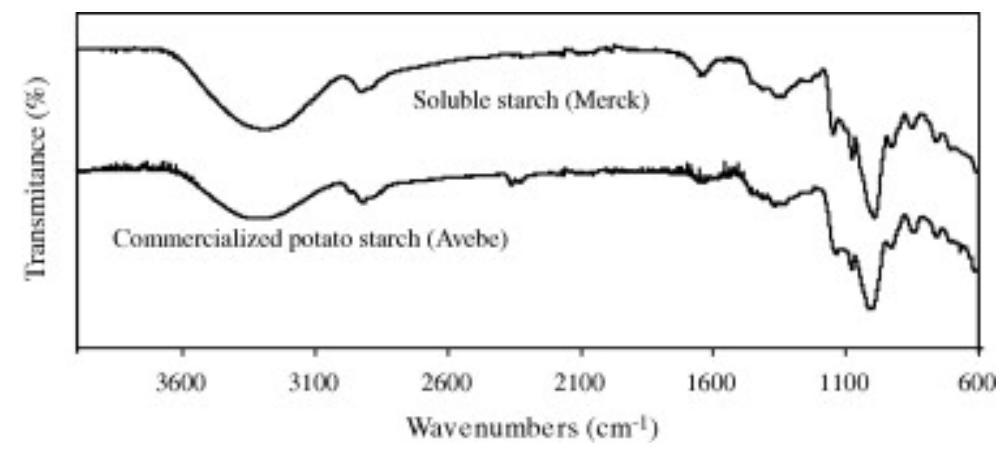

Fig 1. IR spectra of commercialized potato starch from AVEBE and soluble starch from Merck.

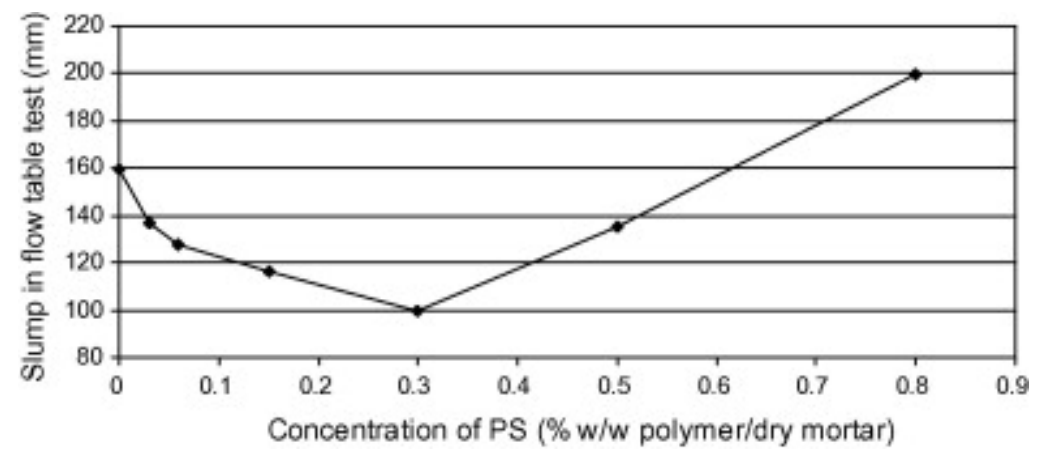

Fig 2. Slump results in flow table test vs. concentration of potato starch.

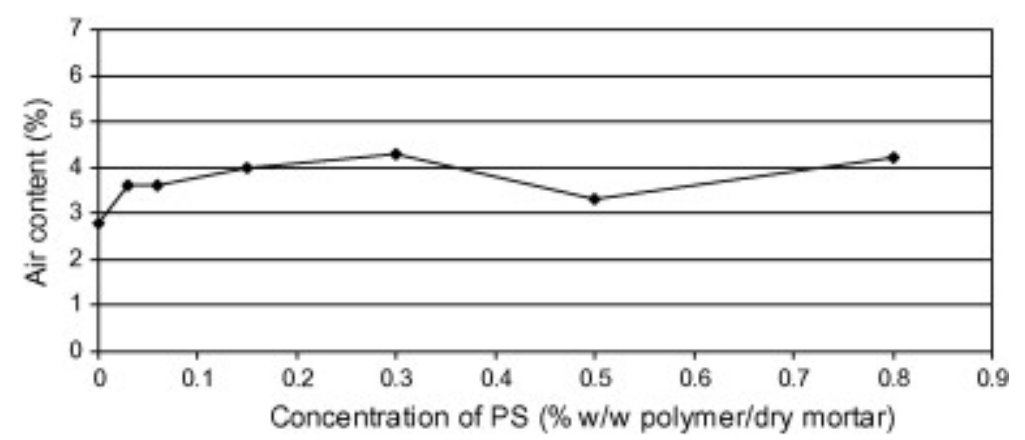

Fig 3. Air content of mortars vs. concentration of potato starch.

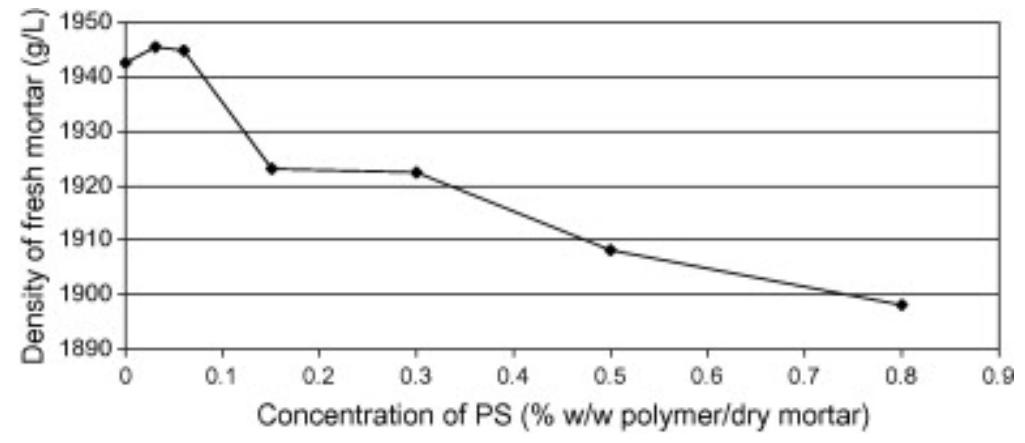

Fig. 4 Density of the fresh mixtures vs. concentration of potato starch. 


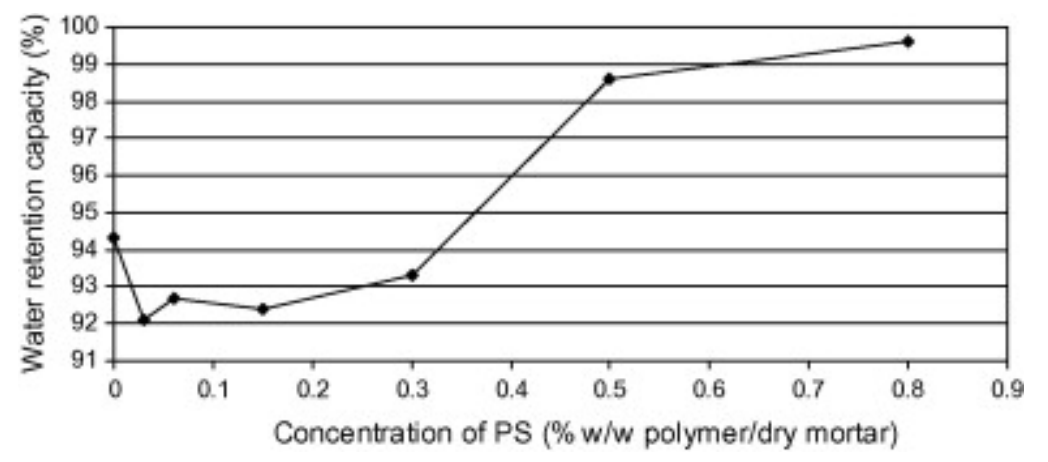

Fig 5. Water retention capacity of the mortars vs. concentration of potato starch.

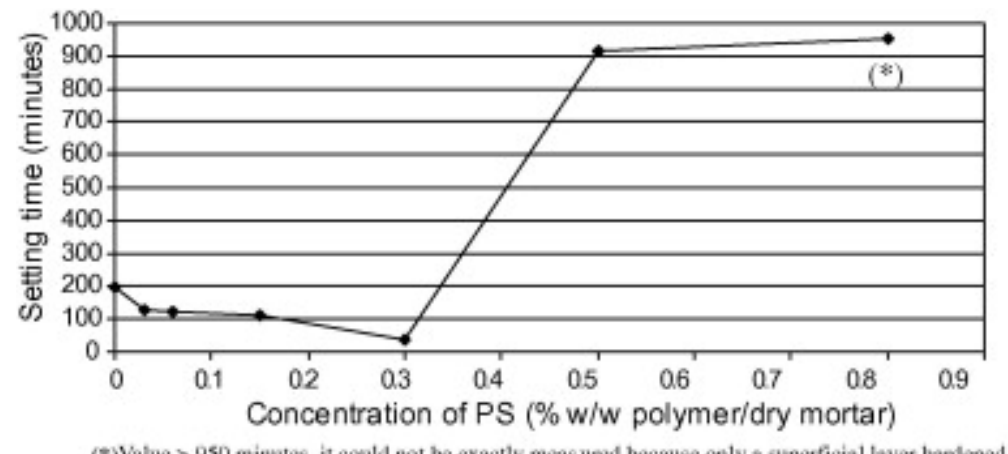

(*)Value > 950 minutes, it could not be exactly meas ured because only a superficial layer hardened while the bulk of the mortar stood fresh.

Fig 6 Setting time of mortars vs. concentration of potato starch. 


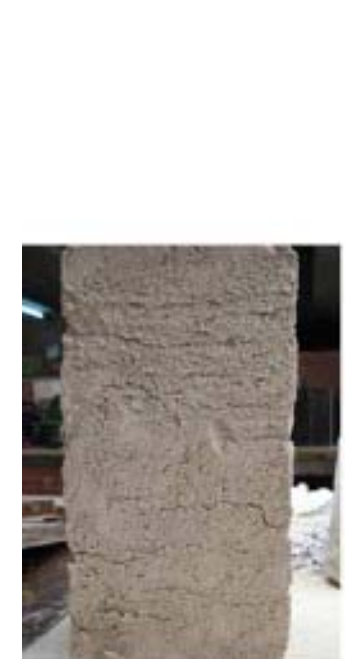

a

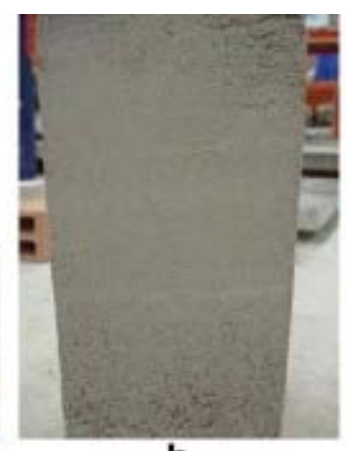

b

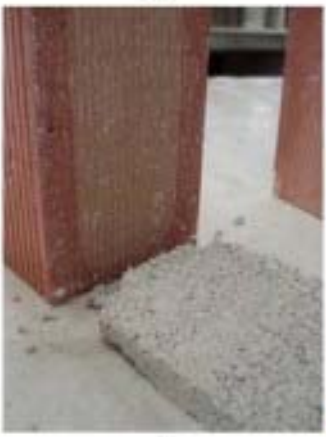

e
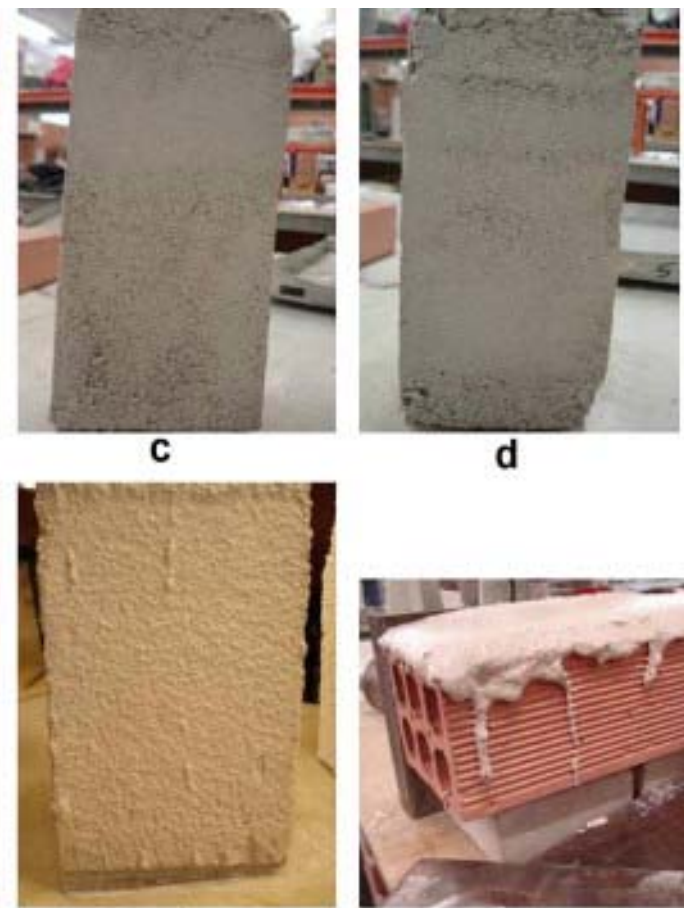

f

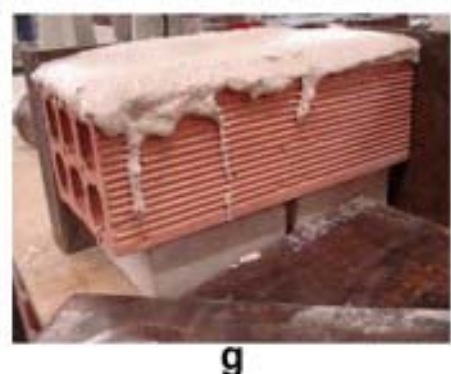

Fig 7. Evolution of mortars on bricks: (a) REF; (b) PS-1; (c) PS-2, (d) PS-3, (e) PS-4, (f)PS-5, and (g) PS-6.

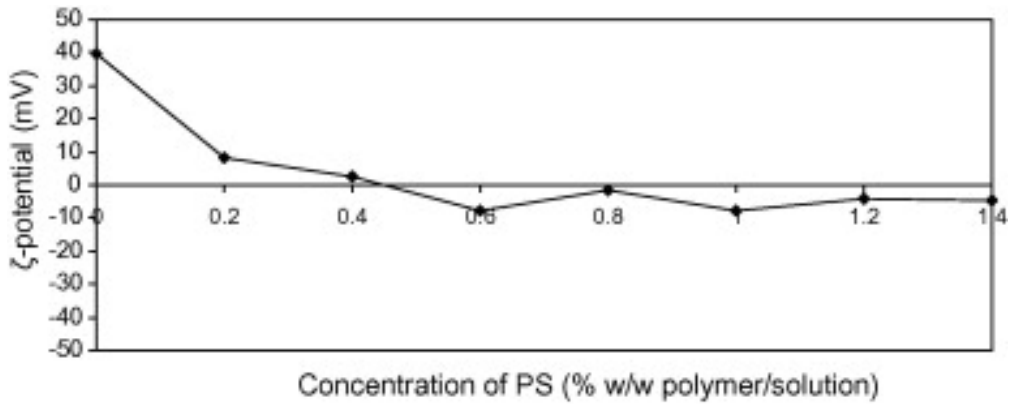

Fig 8. Z-Potential of samples vs. concentration of potato starch. 


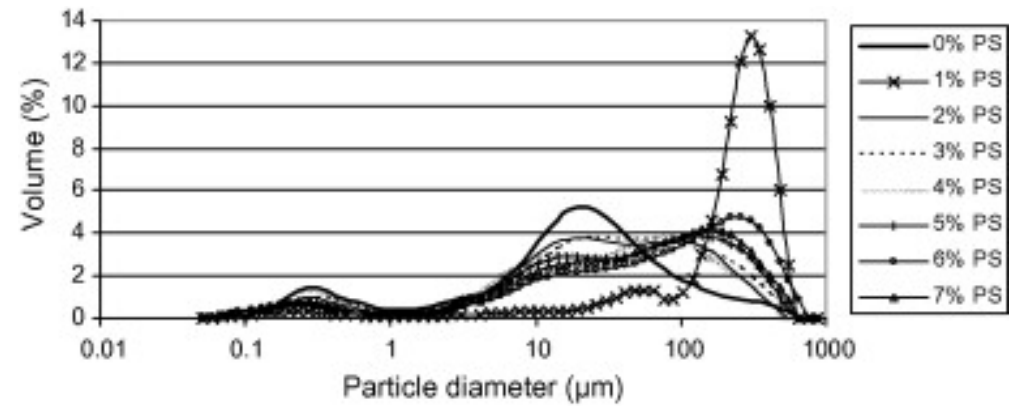

Fig 9. Particle size distribution of lime pastes with different PS dosages (amounts of PS are expressed as percentages of lime weight).
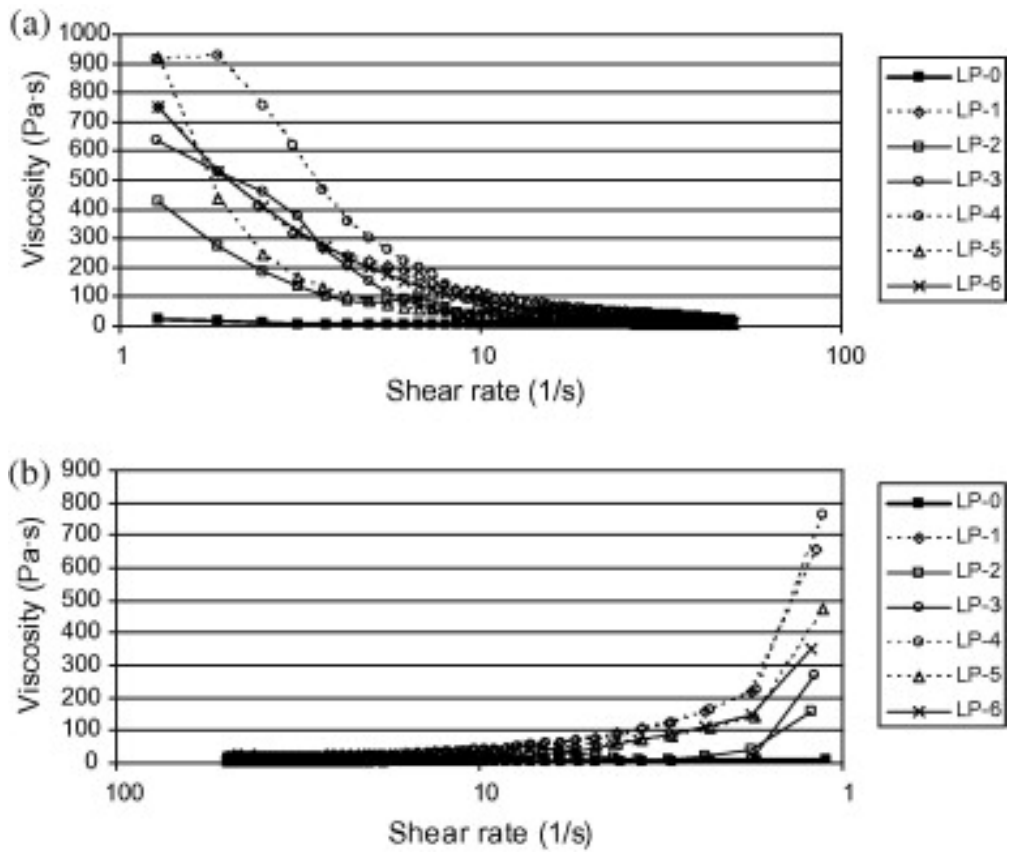

Fig 10. Apparent viscosity of lime pastes (LP) without admixture (LP-0) and with increasing amounts of PS (from LP-1 to LP-6): (a) during increasing shear rate step; (b) during decreasing shear rate step. 